\title{
Анализ звукоизоляционных качеств каркасно-обшивных перегородок
}

\author{
Н.А.Минаева, НИИСФ РААСН, Москва
}

В данной статье приведены результаты испытаний в реверберационной камере НИИСФ каркасно-обшивных перегородок предприятия «КНАУФ» с обшивками из гипсокартонных листов (ГКЛ) и гипсоволокнистых листов влагостойких (ГВЛВ) в один и два слоя, выполненных на одинарных металлических каркасах шириной 50 и 100 мм с заполнением воздушного промежутка минераловатными плитами объёмным весом 15 кг/м². Проведён сравнительный анализ частотных характеристик звукоизоляции перегородок в зависимости от объёмного веса их обшивок. Также в статье приводится сравнительный анализ частотных характеристик звукоизоляции перегородок в зависимости от толщины звукопоглощающего материала, которым заполнялся воздушный промежуток перегородок. Результатом данных исследований является приведённый обширный каталог каркасно-обшивных перегородок с использованием ГКЛ и ГВЛВ, который позволяет выбрать удобную для потребителя конструкцию с требуемым в соответствии с нормативными документами индексом звукоизоляции $R_{\mathrm{w}}$.

Ключевые слова: звукоизоляция, перегородка, обшивка, гипсокартонные листы (ГКЛ), гипсоволокнистые листы влагостойкие (ГВЛВ), звукопоглощающий материа

\section{Analysis of Sound Insulation Qualities of Frame- Sheathing Partition Walls}

\section{N.A.Minaeva, RAACS, Moscow}

The article presents the results of tests of the KNAUF framesheath partitions in the NIISF reverberation chamber, with one and twolayers of gypsum plasterboard (GKL) and gypsum-fiber moistureproof (GVLV) sheets on single metal frames $50 \mathrm{~mm}$ and $100 \mathrm{~mm}$ wide, filling the air gap with mineral wool plates with a volume weight of $15 \mathrm{~kg} / \mathrm{m}^{3}$. The comparative analysis of frequency characteristics of sound insulation of partitions depending on volume weight of their coverings was carried out. The article also provides a comparative analysis of the frequency characteristics of sound insulation of partitions depending on the thickness of the sound-absorbing material, which filled the air gap of partitions. The results of these studies are presented in the catalog of frame-sheath partitions using GKL and GVLV, which allows to choose a user-friendly design with the sound insulation index Rw required in accordance with regulatory documents.

Keywords: sound proofing, partition, panelling, gypsum plasterboard sheets, gypsum-fiber moistureproof sheets, moisture absorbent material.
За последние пятнадцать лет в гражданском строительстве в качестве внутренних ограждающих конструкций большую популярность приобрели каркасно-обшивные (слоистые) перегородки на основе гипсокартонных (ГКЛ) и гипсоволокнистых (ГВЛВ) листов с заполнением воздушного промежутка звукопоглощающими минераловатными плитами. Это объясняется тем, что при применении таких перегородок уменьшаются сроки их возведения и стоимость строительных работ, а также снижается нагрузка на несущие элементы здания за счёт использования более лёгких слоистых конструкций в отличие от более тяжёлых (бетонных, кирпичных и т.д.) однослойных ограждающих конструкций.

Предприятия, выпускающие гипсокартонные листы и минеральную вату, проявляют активный интерес к исследованию каркасно-обшивных перегородок, их нормированию по звукоизолирующим качествам и созданию каталогов своей продукции. Одними из первых, с кем в этой области начал сотрудничать Научно-исследовательский институт строительной физики, были предприятия «КНАУФ». Наши совместные работы позволили исследовать и сертифицировать почти весь номенклатурный ряд конструкций каркасно-обшивных перегородок.

Измерения проводились в реверберационных камерах НИИСФ в соответствии с ГОСТ 27296-2012. «Методы измерения звукоизоляции ограждающих конструкций» [1].

Испытуемая конструкция монтировалась в проёме между камерой высокого уровня (КВУ) и камерой низкого уровня (КНУ). Объем КВУ - 200 м³ , объем КНУ - 112 м³ $^{3}$ размер проёма 4,3×2,5 м. Камера низкого уровня выполнена по принципу «коробка в коробке» - на отдельных фундаментах с резиновыми виброизоляторами, она отделена от испытуемого ограждения и конструкций камеры высокого уровня, чтобы на результаты измерений не влияла косвенная передача звука по примыкающим конструкциям.

На основании измеренных частотных характеристик изоляции воздушного шума (значений звукоизоляции в третьоктавных полосах частот в диапазоне 100-3150 Гц) определялись величины индексов изоляции воздушного шума $R_{\mathrm{w}^{\prime}}$ служащие для оценки звукоизоляции конструкции одним числом. Методика определения индексов $R_{\mathrm{w}}$ приведена в актуализированном СНиП 23-03-2003 «Защита от шума» [2].

Влияние объёмного веса обшивки перегородки на её звукоизоляцию

При испытаниях в качестве обшивок использовались гипсокартонные листы производства «КНАУФ» с объёмным 
весом 850 кг/м³ и гипсоволокнистые листы с объёмным весом $1200 \mathrm{\kappa г} / \mathrm{M}^{3}$.

В таблице 1 приведены частотные характеристики изоляции воздушного шума отдельно взятых листов обшивки. При одинаковой толщине 12,5 мм поверхностная плотность

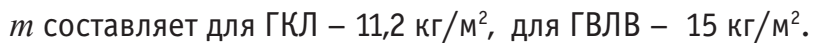

Из таблицы 1 видно, что у гипсокартонных и гипсоволокнистых листов звукоизоляция $R$ от 100 Гц и выше плавно растёт и достигает максимума в третьоктавной полосе со среднегеометрической частотой $f_{1}=1600$ Гц и составила 35 дБ для ГКЛ и 37 дБ - для ГВЛВ. Далее с ростом частоты звукоизо-

Таблица 1. Значения звукоизоляции $R$, дБ, для листов ГКЛ и ГВЛВ

\begin{tabular}{|c|c|c|}
\hline $\begin{array}{l}\text { Среднегеометрическая частота } \\
\text { 1/3-октавной полосы частот, Гц }\end{array}$ & Перегородка из ГКЛ & $\begin{array}{l}\text { Перегородка из } \\
\text { ГВлВ }\end{array}$ \\
\hline 100 & 16 & 17 \\
\hline 125 & 18 & 22 \\
\hline 160 & 22 & 24 \\
\hline 200 & 22 & 27 \\
\hline 250 & 24 & 27 \\
\hline 315 & 25 & 28 \\
\hline 400 & 26 & 29 \\
\hline 500 & 27 & 31 \\
\hline 630 & 29 & 33 \\
\hline 800 & 29 & 34 \\
\hline 1000 & 32 & 35 \\
\hline 1250 & 33 & 36 \\
\hline 1600 & 35 & 37 \\
\hline 2000 & 34 & 36 \\
\hline 2500 & 30 & 30 \\
\hline 3150 & 28 & 28 \\
\hline $\begin{array}{c}\text { Индекс звукоизоляции } \\
\mathrm{R}_{w} \text { дБ }\end{array}$ & 30 & 33 \\
\hline
\end{tabular}

Таблица 2. Значения звукоизоляции $\mathrm{R}$ (дБ) для перегородок с обшивкой из ГКЛ и ГВЛВ

\begin{tabular}{|c|c|c|}
\hline $\begin{array}{c}\text { Среднегеометрическая частота } \\
\text { 1/3-октавной полосы частот, } \\
\text { Гц }\end{array}$ & $\begin{array}{c}\text { Перегородка по } \\
\text { каркасу 50 мм } \\
\text { собшивкой из ГКл }\end{array}$ & $\begin{array}{c}\text { Перегородка по } \\
\text { каркасу } \\
50 \text { мм } \\
\text { с обшивкой из } \\
\text { ГВлВ }\end{array}$ \\
\hline 100 & 15 & 21 \\
\hline 125 & 23 & 28 \\
\hline 160 & 26 & 35 \\
\hline 200 & 33 & 41 \\
\hline 250 & 36 & 54 \\
\hline 315 & 38 & 49 \\
\hline 400 & 43 & 51 \\
\hline 500 & 46 & 53 \\
\hline 630 & 49 & 56 \\
\hline 800 & 53 & 59 \\
\hline 1000 & 54 & 60 \\
\hline 1250 & 56 & 60 \\
\hline 1600 & 56 & 61 \\
\hline 2000 & 55 & 60 \\
\hline 2500 & 47 & 54 \\
\hline 3150 & 42 & 45 \\
\hline$R_{w \prime}$ дБ & 45 & 51 \\
\hline
\end{tabular}

ляция $R$ обоих листов снижается вплоть до граничной частоты нормируемого диапазона $f_{2}=3150$ Гц. Это хорошо согласуется с методом расчёта по Своду правил СП 23-103-2003 [3].

По методике СП частота т. В (максимум частотной характеристики) для ГКЛ и ГВЛВ при объёмной плотности обшивки

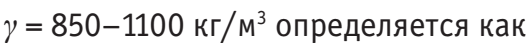

$$
f_{1}=\frac{19000}{h}=\frac{19000}{12,5}=1520 \text { Гц, }
$$

где $h$ - толщина листа обшивки в мм.

Это попадает в третьоктавную полосу со среднегеометрической частотой 1600 Гц и границами 1415-1782 Гц.

Таблица 3. Значения звукоизоляции $R$, дБ, для конструкций толщиной 50 и 100 мм с обшивкой ГКЛ в 1 лист

\begin{tabular}{|c|c|c|}
\hline $\begin{array}{c}\text { Среднегеометрическая частота } \\
\text { 1/3-октавной полосы частот, } \\
\text { Гц }\end{array}$ & $\begin{array}{l}\text { Толщина воздушного } \\
\text { промежутка } \\
\text { с минплитой } 50 \text { мм }\end{array}$ & $\begin{array}{l}\text { Толщина воздушного } \\
\text { промежутка } \\
\text { с минплитой } 100 \text { мм }\end{array}$ \\
\hline 100 & 15 & 25 \\
\hline 125 & 21 & 30 \\
\hline 160 & 27 & 36 \\
\hline 200 & 36 & 39 \\
\hline 250 & 38 & 42 \\
\hline 315 & 41 & 47 \\
\hline 400 & 44 & 49 \\
\hline 500 & 47 & 50 \\
\hline 630 & 49 & 54 \\
\hline 800 & 50 & 57 \\
\hline 1000 & 55 & 59 \\
\hline 1250 & 55 & 58 \\
\hline 1600 & 54 & 59 \\
\hline 2000 & 54 & 59 \\
\hline 2500 & 49 & 52 \\
\hline 3150 & 43 & 45 \\
\hline $\begin{array}{c}\text { Индекс звукоизоляции } \\
\mathrm{R}_{n,} \text { дБ }\end{array}$ & 45 & 51 \\
\hline
\end{tabular}

Таблица 4. Значения звукоизоляции R, дБ, для конструкций толщиной 50 и 100 мм с обшивкой ГКЛ в два листа

\begin{tabular}{|c|c|c|}
\hline $\begin{array}{c}\text { Среднегеометрическая частота } \\
\text { 1/3-октавной полосы частот, } \\
\text { Гц }\end{array}$ & $\begin{array}{c}\text { Толщина } \\
\text { воздушного } \\
\text { промежутка } \\
\text { с минплитой } 50 \text { мм }\end{array}$ & $\begin{array}{c}\text { Толщина } \\
\text { воздушного } \\
\text { промежутка } \\
\text { с минплитой } 100 \text { мм }\end{array}$ \\
\hline 100 & 25 & 36 \\
\hline 125 & 34 & 39 \\
\hline 160 & 34 & 41 \\
\hline 200 & 40 & 43 \\
\hline 250 & 41 & 46 \\
\hline 315 & 43 & 49 \\
\hline 400 & 46 & 52 \\
\hline 500 & 48 & 54 \\
\hline 630 & 53 & 56 \\
\hline 800 & 54 & 58 \\
\hline 1000 & 57 & 60 \\
\hline 1250 & 58 & 61 \\
\hline 1600 & 59 & 62 \\
\hline 2000 & 56 & 61 \\
\hline 2500 & 51 & 56 \\
\hline 3150 & 49 & 51 \\
\hline $\begin{array}{c}\text { Индекс звукоизоляции } \\
\mathrm{R}_{\mathrm{w}} \text { дБ }\end{array}$ & 51 & 54 \\
\hline
\end{tabular}


Таблица 5. Индексы изоляции каркасно-обшивных перегородок, выполненных на одном каркасе

\begin{tabular}{|c|c|c|c|c|c|c|}
\hline $\begin{array}{l}\text { Тип } \\
\text { перего- } \\
\text { родки }\end{array}$ & $\begin{array}{c}\text { Толщина } \\
\text { обшивки, } \\
\text { мм }\end{array}$ & $\begin{array}{l}\text { Толщи- } \\
\text { на пе- } \\
\text { регород- } \\
\text { ки, мм }\end{array}$ & $\begin{array}{l}\text { Толщи- } \\
\text { на } \\
\text { каркаса, } \\
\text { мм }\end{array}$ & $\begin{array}{c}\text { Толщи- } \\
\text { на мин- } \\
\text { ваты, } \\
\text { мм }\end{array}$ & $\begin{array}{l}R_{w r} \\
\text { मБ }\end{array}$ & Перечень помещений \\
\hline \multirow{7}{*}{ 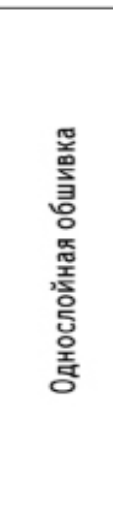 } & \multirow{7}{*}{ 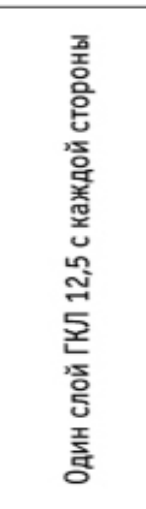 } & 75 & 50 & 50 & 44 & $\begin{array}{l}\text { В квартире межкомнатные } \\
\text { перегородки }\end{array}$ \\
\hline & & 90 & 65 & 50 & 45 & \multirow{3}{*}{$\begin{array}{l}\text { В офисах между кабинетами } \\
\text { и между рабочими } \\
\text { комнатами }\end{array}$} \\
\hline & & \multirow{2}{*}{100} & \multirow{2}{*}{75} & 50 & 45 & \\
\hline & & & & 75 & 46 & \\
\hline & & \multirow{3}{*}{125} & \multirow{3}{*}{100} & 50 & 47 & $\begin{array}{l}\text { В дошкольных учреждениях } \\
\text { между групповыми } \\
\text { комнатами }\end{array}$ \\
\hline & & & & 75 & 48 & $\begin{array}{l}\text { Между кабинетами разных } \\
\text { фирм; между палатами и } \\
\text { кабинетами врачей; между } \\
\text { классами }\end{array}$ \\
\hline & & & & 100 & 50 & \multirow{3}{*}{$\begin{array}{l}\text { Между комнатами } \\
\text { общежитий; между но- } \\
\text { мерами гостиниц класса } \\
\text { менее 3-х звёзд }\end{array}$} \\
\hline \multirow{7}{*}{ 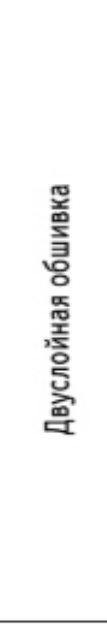 } & \multirow{7}{*}{ 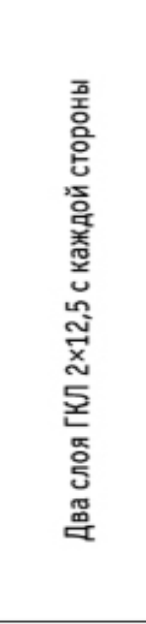 } & 100 & 50 & 50 & 50 & \\
\hline & & 115 & 65 & 50 & 50 & \\
\hline & & \multirow[t]{2}{*}{125} & \multirow[t]{2}{*}{75} & 50 & 51 & $\begin{array}{l}\text { Между номерами для 3- } \\
\text { звёздочных гостиниц; } \\
\text { между номерами и } \\
\text { помещениями общего } \\
\text { пользования }\end{array}$ \\
\hline & & & & 75 & 53 & $\begin{array}{l}\text { Между номерами, между } \\
\text { номерами и помещениями } \\
\text { общего пользования в 4- } \\
\text { и 5-звёздочных гостиницах }\end{array}$ \\
\hline & & \multirow{3}{*}{150} & \multirow{3}{*}{100} & 50 & 54 & \multirow{2}{*}{$\begin{array}{l}\text { Между операционными; } \\
\text { между операционными и } \\
\text { другими помещениями }\end{array}$} \\
\hline & & & & 75 & 54 & \\
\hline & & & & 100 & 58 & $\begin{array}{l}\text { Между музыкальными } \\
\text { классами высших учебных } \\
\text { заведений }\end{array}$ \\
\hline \multirow{7}{*}{ 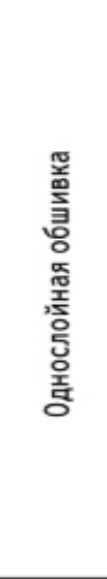 } & \multirow{7}{*}{ 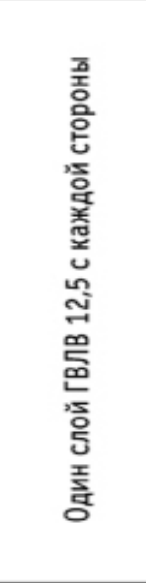 } & 75 & 50 & 50 & 51 & \multirow{5}{*}{$\begin{array}{l}\text { Между номерами для 3- } \\
\text { звёздочных гостиниц; } \\
\text { между номерами и } \\
\text { помещениями общего } \\
\text { пользования }\end{array}$} \\
\hline & & 90 & 65 & 50 & 51 & \\
\hline & & 100 & 75 & 50 & 51 & \\
\hline & & 100 & 13 & 75 & 52 & \\
\hline & & & & 50 & 51 & \\
\hline & & 125 & 100 & 75 & 53 & $\begin{array}{l}\text { Между номерами, между } \\
\text { номерами и помещениями } \\
\text { общего пользования в 4- и } \\
\text { 5-звёздочных гостиницах }\end{array}$ \\
\hline & & & & 100 & 54 & $\begin{array}{l}\text { Между операционными; } \\
\text { между операционными и } \\
\text { другими помещениями }\end{array}$ \\
\hline \multirow{7}{*}{ 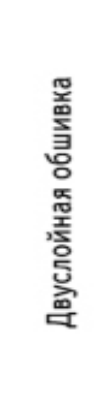 } & \multirow{7}{*}{ 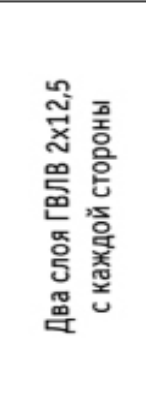 } & 100 & 50 & 50 & 57 & \multirow{7}{*}{$\begin{array}{l}\text { Между музыкальными } \\
\text { классами высших учебных } \\
\text { заведений и в любых } \\
\text { помещениях с } \\
\text { повышенными } \\
\text { требованиями к } \\
\text { звукоизоляции. }\end{array}$} \\
\hline & & 115 & 65 & 50 & 57 & \\
\hline & & 125 & 75 & 50 & 57 & \\
\hline & & 125 & קו & 75 & 57 & \\
\hline & & \multirow{3}{*}{150} & \multirow{3}{*}{100} & 50 & 56 & \\
\hline & & & & 75 & 57 & \\
\hline & & & & 100 & 58 & \\
\hline
\end{tabular}


Частота провала частотной характеристики звукоизоляции обшивки:

$$
f_{\mathrm{c}}=\frac{38000}{h}=\frac{38000}{12,5}=3040 \text { Гц } \approx 3150 \text { Гц. }
$$

Индекс изоляции составил $R_{\mathrm{w}}=30$ дБ для ГКЛ и $R_{\mathrm{w}}=33$ дБ для ГВЛВ.

В целом, можно считать, что ГВЛВ по сравнению с ГКЛ имеют преимущество по звукоизоляции практически во всём исследуемом диапазоне частот.

В таблице 2 приведены частотные характеристики звукоизоляции двух перегородок, выполненных по металлическому каркасу 50 мм с заполнением воздушного промежутка минераловатными плитами с объёмным весом 15 кг/м ${ }^{3}$ и толщиной 50 мм с обшивкой из ГКЛ и ГВЛВ по одному листу с каждой стороны.

По результатам измерений каркасно-обшивная перегородка с обшивкой из ГКЛ имеет индекс изоляции $R_{\mathrm{w}}=43$ дБ, а с обшивкой из ГВЛВ $-R_{\mathrm{w}}=51$ дБ, то есть индекс изоляции перегородки с ГВЛВ, у которой объёмный вес обшивки составляет 1100 кг/м³, на 6 дБ выше, чем для перегородки с обшивкой из ГКЛ, объёмный вес которой составляет 850 кг/ $\mathrm{M}^{3}$. Во всем частотном диапазоне звукоизоляция перегородки с ГВЛВ выше звукоизоляции перегородки с ГКЛ на 1-10 дБ.

Так же были проведены сравнительные измерения звукоизоляции перегородок с обшивкой из ГКЛ и ГВЛВ (по два слоя с каждой стороны) при толщине каркаса 100 мм с заполнением воздушного промежутка минплитами толщиной 100 мм. Замена гипсокартонных листов на ГВЛВ дала увеличение индекса изоляции $R_{\text {w }}$ на 1 дБ (с 58 дБ до 59 дБ). То есть при высокой звукоизоляции перегородки увеличение объёмного веса обшивки незначительно увеличивает её звукоизоляцию.

\section{Влияние толщины звукопоглощающего слоя на звуко- изоляцию перегородки}

Другим существенным параметром, влияющим на звукоизоляцию каркасно-обшивной перегородки, является толщина звукопоглощающего материала, которым заполняется воздушный промежуток перегородки [4; 5].

При прохождении звуковых волн через двойное ограждение с воздушным промежутком образуются стоячие волны, которые являются жёсткими связями между двумя панелями. При заполнении воздушного промежутка между обшивками звукопоглощающим материалом достигается подавление резонансов в этом воздушном пространстве за счёт поглощения звуковой энергии при многократном прохождении в нём (звукопоглощающем материале) отражённых волн. Известно, что поглощение звуковой энергии оценивается коэффициентом звукопоглощения, и чем он выше, тем большего эффекта звукоизоляции конструкции можно ожидать.

Для определения влияния толщины звукопоглощающего слоя были проведены испытания перегородок с различной толщиной воздушного промежутка: 50 и 100 мм.

В таблице 3 приведены сравнительные частотные характеристики звукоизоляции перегородок с металлическими каркасами
50 и 100 мм с обшивкой гипсокартонными листами по одному слою с каждой стороны при заполнении воздушного промежутка минплитами толщиной 50 и 100 мм плотностью 15 кг/м³.

Индекс изоляции для этих перегородок увеличился с 45 дБ для конструкции толщиной 50 мм до 51 дБ для конструкции толщиной 100 мм, при этом частотная характеристика звукоизоляции перегородки с минплитой 100 мм превышает звукоизоляцию перегородки с минплитой 50 мм во всём диапазоне частот от 3 до 10 дБ.

В таблице 4 приведены сравнительные частотные характеристики звукоизоляции перегородок с металлическим каркасом 50 и 100 мм при заполнении воздушного промежутка минплитами толщиной 50 и 100 мм, обшитые ГКЛ по два листа с каждой стороны.

Индекс изоляции перегородки с минватой толщиной 50 мм составил $R_{\mathrm{w}}=51$ дБ, индекс изоляции перегородки с минватой толщиной 100 мм увеличился до 54 дБ.

Как видим, влияние толщины звукопоглощающего слоя также снижается при увеличении абсолютной величины звукоизоляции конструкции. Так, в первом случае увеличение толщины минплиты привело к увеличению индекса изоляции на 6 дБ, а во втором случае - всего на 3 дБ.

Таким образом, изменяя ширину воздушного промежутка и количество слоёв обшивки, было обследовано более 20 конструкций. Индексы звукоизоляции составили: минимальный индекс $R_{\mathrm{w}}=44$ дБ - для самой простой конструкции с обшивкой из ГКЛ по одному листу с каждой стороны и толщиной воздушного промежутка с минватой 50 мм; максимальный $R_{\mathrm{w}}=58$ дБ - для перегородок с обшивкой по два слоя ГКЛ и минватой 100 мм.

Результатом проведённых исследований является обширный каталог каркасно-обшивных перегородок с использованием ГКЛ и ГВЛВ, который позволяет выбрать удобную для потребителя конструкцию с требуемым индексом звукоизоляции $R_{\mathrm{w}}$ в соответствии с нормативными документами.

\section{Лumepamypa}

1. ГОСТ 27296-2012. Здания и сооружения. Методы измерения звукоизоляции ограждающих конструкций. - М.: Стандартинформ, 2014.

2. Свод правил СП 51.13330.2011. Защита от шума. Актуализированная редакция СНиП 23-03 -2003 / Министерство регионального развития Российской Федерации. - М., 2011.

3. СП 23-103-2003. Проектирование звукоизоляции ограждающих конструкций жилых и общественных зданий. - М.: Госстрой России, 2004.

4. Минаева Н.А. Экспериментальные исследования звукоизоляции пазогребневых плит, обшитых гипсокартонными листами / Н.А. Минаева // Academia. Архитектура и строительство. - 2010. - № 3. - С. 194-197.

5. Кочкин А.А. Исследование изоляции воздушного шума двойными ограждающими конструкциями / А.А. Кочкин, А.В. Киряткова, И.Л. Шубин // Бюллетень строительной техники. - 2018. - № 6 (1006). - С. 20-21. 


\section{Literature}

1. GOST 27296-2012. Zdaniya i sooruzheniya. Metody izmereniya zvukoizolyatsii ograzhdayushhih konstruktsij. M.: Standartinform, 2014.

2. Svod pravil SP 51.13330.2011. Zashhita ot shuma. Aktualizirovannaya redaktsiya SNiP 23-03 -2003 / Ministerstvo regional'nogo razvitiya Rossijskoj Federatsii. - M., 2011.

3. SP 23-103-2003. Proektirovanie zvukoizolyatsii ograzhdayushhih konstruktsij zhilyh i obshhestvennyh zdanij. - M.: Gosstroj Rossii, 2004.
4. Minaeva N.A. Eksperimental'nye issledovaniya zvukoizolyatsii pazogrebnevyh plit, obshityh gipsokartonnymi listami / N.A. Minaeva // Academia. Arhitektura i stroitel'stvo. - 2010. - № 3. - S. 194-197.

5. Kochkin A.A. Issledovanie izolyatsii vozdushnogo shuma dvojnymi ograzhdayushhimi konstruktsiyami / A.A. Kochkin, A.V. Kiryatkova, I.L. Shubin // Byulleten' stroitel'noj tehniki. - 2018. - № 6 (1006). - S. 20-21.

Минаева Нина Александровна (Москва). Старший научный сотрудник ФГБУ «Научно-исследовательский институт строительной физики РАAСН» (127238, Москва, Локомотивный пр., д. 21. НИИСФ РААСН). Сфера научных интересов: борьба с шумами в жилых и общественных зданиях. Автор 10 научныхтрудов. Тел.: +7 (916) 351-14-49. E-mail: ninaminaeva@gmail.com.

Minaeva Nina Alexandrovna (Moscow). Senior Researcher at the Research Institute of Building Physics of RAACS (127238, Moscow, Lokomotivny proezd, 21. NIISF). Research interests: noise protection of residential and public buildings. The author of 10 scientific publications. Tel.: +7 (916) 351-14-49. E-mail: ninaminaeva@gmail.com. 